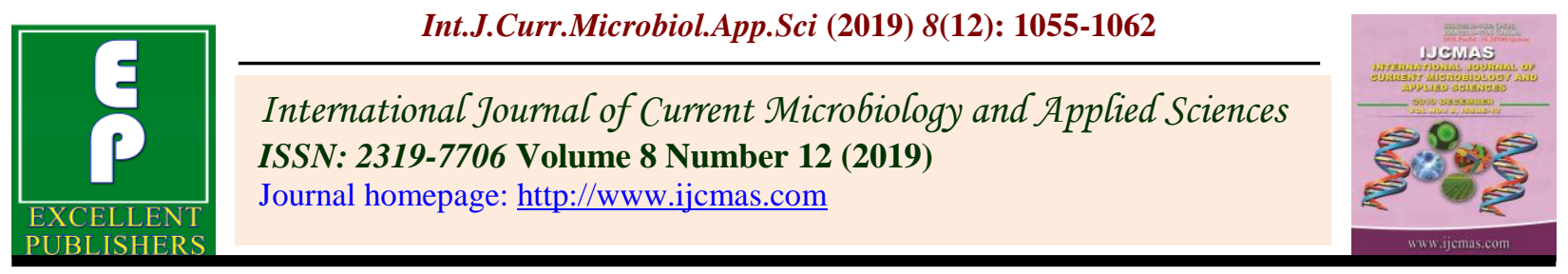

Original Research Article

https://doi.org/10.20546/ijcmas.2019.812.134

\title{
Beneficial Microbial Load under Organic Cotton Production System
}

\author{
Rudragouda F. Channagouda* \\ Krishi Vigyan Kendra, Babbur Farm, Hiriyur University of Agricultural and Horticultural \\ Sciences, Shivamoga, Karnataka, India \\ *Corresponding author
}

\begin{tabular}{|l|}
\hline Key w or d s \\
Uptake and soil \\
availability of N, P, \\
K and microbial \\
population
\end{tabular}

\section{A B S T R A C T}

The field experiment was carried out at MARS, Dharwad during Kharif, 2010-11 and 2011-12 to study the "Beneficial microbial load under organic cotton production system "Among the nutrient management practices, integrated application of EC (1/3) + VC (1/3) + gliricidia GLM (1/3) equivalent to RDF recorded significantly higher Integrated application of EC $(1 / 3)+$ VC $(1 / 3)+$ gliricidia GLM (1/3) equivalent to RDF recorded significantly higher bacteria, fungal, actinomycetes, $\mathrm{N}_{2}$-fixers, enzymes mainly phosphatase and dehydrogenase activity and soil respiration rate

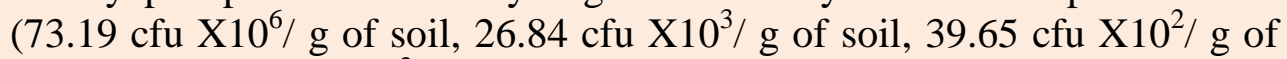

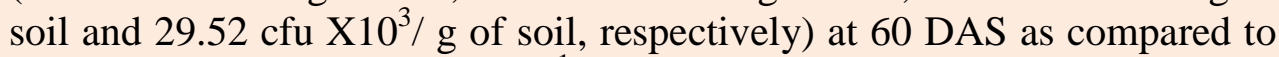
application of FYM @ $5 \mathrm{t} \mathrm{ha}^{-1}+\mathrm{RDF}$. Among the different treatment combinations, application of EC (1/3) + VC (1/3) + gliricidia GLM (1/3) equivalent to RDF with foliar spray of panchagavya @ 5\% recorded significantly higher bacteria, fungi, actinomycetes and $\mathrm{N}_{2}$-fixers over RDF + FYM

\section{Introduction}

Currently, the energy crises associated with hike in prices of $\mathrm{N}, \mathrm{P}_{2} \mathrm{O}_{5}$ and $\mathrm{K}_{2} \mathrm{O}$ fertilizers has made the use of chemical fertilizers in crop production not only costly but also in short supply. It is imperative to develop and make use of on-farm organic sources of nutrients to maintain healthy crop growth and obtain sustainable yield and quality apart from reduction in cost of chemical fertilizers. It is worth to note that nutrient management through organics play a major role in maintaining soil health due to build up of soil organic matter, beneficial microbes and enzymes, besides improving soil physical, chemical and biological properties. To achieve sustainable soil fertility and crop productivity, the role of green manures, organic manures, biofertilizers and other nutrient sources like 
use of fermented organic nutrients mainly panchagavya, jeevamruth, cow urine, vermiwash, bio-digester etc, are becoming popular among the farmers. Organic agriculture in the world has emerged as an alternative to the chemicals oriented intensive modern agriculture. The global retail market of organic cotton has increased from 583 million to 4.3 billion in 2009 with an annual growth rate of $3.8 \%$ (Anon., 2015). In India, cotton is grown over an area of about 11.14 m.ha with a total production of $34.93 \mathrm{~m}$. bales (Anon., 2015). India ranks fifth in area and third in production of cotton after USA and China. The productivity of cotton is $510 \mathrm{~kg}$ of lint $\mathrm{ha}^{-1}$ which is much lower than the world average of $621 \mathrm{~kg} \mathrm{ha}^{-1}$. Among the cotton growing states, Karnataka ranks fifth with an area of 3.90 lakh ha and sixth in production with 9.0 lakh bales of lint with an average productivity of $392 \mathrm{~kg}$ of lint ha $\mathrm{h}^{-1}$.

Presently, the chemical fertilizers are the major source of nutrients but escalating cost, coupled with increasing demand of chemical fertilizers and depleting soil health necessitates the safe and efficient use of organics in crop production. These practices gaining much popularity to enhance and maintain soil health for obtaining sustainable crop yields. The crop management practices such as cultivation, cultural practices, crop rotation, residue management and organic manures exert a considerable influence on the level of organic matter retention in soil over a period of time, regulation of soil microbial biomass, nutrient cycling and organic matter turnover. The enhancement of soil microbial biomass is known to influence crop productivity and nutrient cycling. Application of compost, vermicompost, compost, green manures and liquid organic manures are known to harness the beneficial micro flora and suppress soil pathogens (Bhawalkar and Bhawalkar, 1991). In this context, to field experiment were carried out to study the beneficial microbial load in organic production system.

\section{Materials and Methods}

The field experiment was conducted at MARS, Dharwad during 2010-11 and 2011-12 to study the "Effect of organic manures, green leaf manures, liquid organic manures and micronutrients on yield and economics of cotton". The soil of the experiment site was medium deep black, having medium carbon $(0.48 \%)$ and available NPK (264.70:21.80: 285.30 NPK kg ha-1). The experiment was laid out in split plot design with three replications. The main plot comprises of three manurial treatments as $\mathrm{M}_{1}$ : Recommended dose of fertilizer (RDF) (80:40:40 N:P $\mathrm{P}_{5}: \mathrm{K}_{2} \mathrm{O} \mathrm{kg} \mathrm{ha}{ }^{-1}$ + FYM @5 t ha $\left.{ }^{-1}\right), \mathrm{M}_{2}$ : EC (1/3) + VC (1/3) + $\operatorname{GLM}(1 / 3)$ equivalent to $\mathrm{RDN} \mathrm{M}_{3}$ : $\mathrm{EC}(1 / 3)+$ $\mathrm{VC}(1 / 3)+\mathrm{GLM}(1 / 3)$ equivalent to RDF and sub plot consists of five liquid organic manures treatments are $\mathrm{L}_{1}$ : Foliar application of panchagavya @ 5\% at sympodial branching, square, flower and boll development stages, $\mathrm{L}_{2}$ : Foliar application of bio-digester@20\%, L3: Foliar application of cow urine@10\%, L4: Foliar application of vermiwash, L5: Foliar application borax @ $0.2 \%+\mathrm{MgSO}_{4}$ and one control treatment was $\mathrm{T}_{1}$ : Recommended dose of fertilizer (RDF) (80:40:40 N: $\mathrm{P}_{2} \mathrm{O}_{5}: \mathrm{K}_{2} \mathrm{O} \mathrm{kg} \mathrm{ha}{ }^{-1}+\mathrm{FYM} @ 5 \mathrm{t}$ $\left.\mathrm{ha}^{-1}\right)$. As per the treatments the organic manures equivalent to RDN and RDF through farm yard manure, enriched compost $(50 \%)$, green leaf manure were applied 15 days before sowing and 50\% vermicompost was spot applied to the soil before dibbling of cotton seeds and top dressing with remaining $50 \%$ of vermicompost was done at 60 DAS. The chemical fertilizers as per the recommended package alone and along with farm yard manure were applied to the check treatments. The seeds were treated with cow urine, Azospirilum, Phosphate solubalizing bacteria, Pseudomonas striata, Trichoderma and cow 
dung slurry before sowing. The seed of Hybrid cotton DHH-11 was obtained from ARS Dharwad (ARS, Hebballi) and were hand dibbled with two cotton seeds per hill on 12 , July, 2010 in $1^{\text {st }}$ year and 8, June, 2011 in $2^{\text {nd }}$ year. The soil adhering to the roots was carefully collected and used for enumeration of total bacteria, fungi and actinomycetes, by standard serial dilution plate count technique using soil extract agar for bacteria count (Bunt and Rovira, 1955), Martin's Rose Bengal agar for fungi (Martin, 1950) and Kusters agar for actinomycetes (Kuster and Williams, 1964). The microbial populations were expressed as number of colony farming units per gram dry weight of soil.

\section{Results and Discussion}

Integrated application of EC (1/3) + VC (1/3) + gliricidia GLM (1/3) equivalent to RDF recorded significantly higher bacteria, fungal, actinomycetes, phosphorus solubilising bacteria, $\mathrm{N}_{2}$-fixers, enzymes mainly phosphatase and dehydrogenase activity and soil respiration rate $\left(73.19 \mathrm{cfu} \times 10^{6} / \mathrm{g}\right.$ of soil, $26.84 \mathrm{cfu} X 10^{3} / \mathrm{g}$ of soil, $39.65 \mathrm{cfu} \times 10^{2} / \mathrm{g}$ of

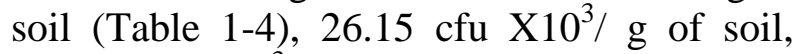
$29.52 \mathrm{cfu} X 10^{3} / \mathrm{g}$ of soil, $25.01 \mu \mathrm{pnp} / \mathrm{g}$ of soil/hr, $11.99 \mu \mathrm{TPF} / \mathrm{g}$ of soil/day, and 9.51 $\mathrm{mg}$ of $\mathrm{C}$ or $\mathrm{CO}_{2 /} \mathrm{hr} / 100 \mathrm{~g}$ of soil respectively) at 60 DAS as compared to application of FYM @ $5 \mathrm{t} \mathrm{ha}^{-1}+\mathrm{RDF}$. The foliar spray of panchagavya @ 5\% in combination with organic manures recorded significantly higher population of bacteria, fungi, actinomycetes, $\mathrm{N}_{2}$-fixers and PSM, phosphatase and dehydrogenase enzyme activity and soil respiration rate over foliar spray of biodigester@20\% with organic manures and was on par with borax @0.2\%+ $\mathrm{MgSO}_{4} @$ $1 \%$ and vermiwash @ $20 \%$. Among the different treatment combinations, application of EC (1/3) + VC (1/3) + gliricidia GLM (1/3) equivalent to RDF with foliar spray of panchagavya @ 5\% recorded significantly higher bacteria, fungi, actinomycetes, $\mathrm{N}_{2^{-}}$ fixers and P-solubilizer, phosphatase and dehydrogenase enzyme activity and soil respiration rate over RDF + FYM and was on par with EC $(1 / 3)+\mathrm{VC}(1 / 3)+$ gliricidia GLM (1/3) equivalent to RDF with borax @ $0.2 \%+\mathrm{MgSO}_{4} @ 1 \%, \mathrm{EC}(1 / 3)+\mathrm{VC}(1 / 3)+$ gliricidia GLM (1/3) equivalent to RDF with vermiwash@ 20\% and EC (1/3) + VC (1/3) + gliricidia GLM (1/3) equivalent to RDF with cow urine @ 10\%. The enhanced soil microbial activity as indicated by both population, microbial diversity and enzymatic activity was mainly due to favourably soil environment, sufficient energy in the form of carbon and protein sources with organic sources of nutrition. These results are in conformity with the findings of

Solaiappan (2002) who opined that, the addition of organic manures have improved the microbial activity and enhanced the availability of native and applied nutrients which in turn increased the yield of cotton. Higher dehydrogenase and phosphatase activity was observed with higher levels of organic matter, narrow $\mathrm{C}: \mathrm{N}$ ratio. This facilitated the greater release and availability of micronutrients in the soil. This has influenced higher uptake of nutrients in above treatments and improved crop performances indicated by ultimately resulted in higher kapas yield of cotton. These results are in confirmation with the findings of Kavallappa (1989) and Singaram and Kamala (1995). There has been an increasing interest in the soil enzymes as indicators of soil fertility, as the soil enzyme activity depends on numerous factors such as climate, amendment type, cultivation practices, crop type and edaphic properties. Naseby and Lynch (1997) considered enzymatic determinations as more useful than microbial population measures. 
Table.1 Bacteria (cfuX10 / g of soil) and fungal (cfuX10 $3 / \mathrm{g}$ of soil) population observed in cotton soil as influenced by organic manures, GLM, liquid organic manures and micronutrients

\begin{tabular}{|c|c|c|c|c|c|c|c|c|c|c|c|c|}
\hline \multirow{3}{*}{ Treatment } & \multicolumn{4}{|c|}{2010} & \multicolumn{4}{|c|}{2011} & \multicolumn{4}{|c|}{ Pooled } \\
\hline & \multicolumn{2}{|c|}{ Bacterial population } & \multicolumn{2}{|c|}{ Fungal population } & \multicolumn{2}{|c|}{ Bacterial population } & \multicolumn{2}{|c|}{ Fungal population } & \multicolumn{2}{|c|}{ Bacterial population } & \multicolumn{2}{|c|}{ Fungal population } \\
\hline & 60 DAS & 90DAS & 60 DAS & 90DAS & 60 DAS & 90DAS & 60 DAS & 90DAS & 60 DAS & 90DAS & 60 DAS & 90DAS \\
\hline \multicolumn{13}{|c|}{ Organic Manure (M) } \\
\hline $\mathrm{M}_{1}$ & $65.52 \mathrm{~b}$ & $62.73 c$ & $23.00 \mathrm{~b}$ & $20.67 b$ & $66.95 c$ & $64.60 \mathrm{c}$ & $25.28 \mathrm{~b}$ & $23.10 \mathrm{~b}$ & $66.23 c$ & $63.67 \mathrm{c}$ & $24.14 c$ & $21.88 \mathrm{c}$ \\
\hline $\mathrm{M}_{2}$ & $68.86 \mathrm{a}$ & $67.21 \mathrm{~b}$ & $23.73 b$ & $21.53 b$ & $71.61 \mathrm{~b}$ & $69.99 b$ & $26.00 \mathrm{~b}$ & $23.81 \mathrm{~b}$ & $70.24 b$ & $68.60 \mathrm{~b}$ & $24.87 \mathrm{~b}$ & $22.67 b$ \\
\hline $\mathrm{M}_{3}$ & $71.25 \mathrm{a}$ & $68.75 \mathrm{a}$ & $25.53 a$ & $22.53 \mathrm{a}$ & $75.13 a$ & $73.00 \mathrm{a}$ & $28.15 \mathrm{a}$ & $25.95 a$ & $73.19 \mathrm{a}$ & $70.87 \mathrm{a}$ & $26.84 \mathrm{a}$ & $24.24 \mathrm{a}$ \\
\hline S.Em. \pm & 0.697 & 0.187 & 0.301 & 0.225 & 0.241 & 0.135 & 0.255 & 0.261 & 0.437 & 0.153 & 0.0523 & 0.048 \\
\hline \multicolumn{13}{|c|}{ Foliar spray of liquid manures + micronutrients (L) } \\
\hline $\mathrm{L}_{1}$ & $69.21 \mathrm{a}$ & $67.22 \mathrm{a}$ & $24.11 \mathrm{a}$ & $21.67 \mathrm{a}$ & $72.16 \mathrm{a}$ & $68.79 a$ & $26.21 \mathrm{a}$ & $24.00 \mathrm{a}$ & $70.69 \mathrm{a}$ & $68.01 \mathrm{a}$ & $25.16 \mathrm{a}$ & $22.83 a$ \\
\hline $\mathrm{L}_{2}$ & $67.33 \mathrm{a}$ & $64.44 \mathrm{~b}$ & $23.56 \mathrm{a}$ & $21.11 \mathrm{a}$ & $69.44 b$ & $68.90 \mathrm{a}$ & $26.17 \mathrm{a}$ & $24.00 \mathrm{a}$ & $68.39 \mathrm{a}$ & $66.67 \mathrm{a}$ & $24.86 \mathrm{a}$ & $22.55 \mathrm{a}$ \\
\hline $\mathrm{L}_{3}$ & $68.44 a$ & $66.33 a$ & $24.11 \mathrm{a}$ & $21.56 \mathrm{a}$ & 70.88ab & $69.37 \mathrm{a}$ & $26.74 a$ & $24.55 \mathrm{a}$ & $69.66 \mathrm{a}$ & $67.85 \mathrm{a}$ & $25.43 a$ & $23.05 \mathrm{a}$ \\
\hline $\mathrm{L}_{4}$ & $68.72 a$ & $66.50 \mathrm{a}$ & $24.22 \mathrm{a}$ & $21.67 \mathrm{a}$ & 71.79ab & $69.46 \mathrm{a}$ & $26.53 a$ & $24.33 a$ & $70.26 \mathrm{a}$ & $67.98 \mathrm{a}$ & $25.37 \mathrm{a}$ & $23.00 \mathrm{a}$ \\
\hline $\mathrm{L}_{5}$ & $69.00 \mathrm{a}$ & $66.66 \mathrm{a}$ & $24.44 a$ & $21.89 \mathrm{a}$ & $71.87 \mathrm{ab}$ & $69.46 a$ & $26.74 a$ & $24.55 \mathrm{a}$ & $70.44 a$ & $68.06 \mathrm{a}$ & $25.59 \mathrm{a}$ & $23.22 \mathrm{a}$ \\
\hline S.Em. \pm & 1.063 & 0.96 & 0.463 & 0.456 & 0.817 & 0.617 & 0.349 & 0.351 & 0.841 & 0.583 & 0.249 & 0.225 \\
\hline \multicolumn{13}{|c|}{ Interactions (MXL) } \\
\hline $\mathrm{M}_{1} \mathrm{~L}_{1}$ & $66.00 \mathrm{~b}-\mathrm{e}$ & $64.00 \mathrm{~cd}$ & $23.00 \mathrm{~cd}$ & $21.00 \mathrm{a}-\mathrm{c}$ & $67.83 c-e$ & $65.53 \mathrm{~cd}$ & $25.39 \mathrm{c}$ & $23.16 \mathrm{c}$ & $66.91 \mathrm{c}-\mathrm{f}$ & $64.77 \mathrm{~cd}$ & $24.20 \mathrm{~b}$ & $22.08 b$ \\
\hline $\mathrm{M}_{1} \mathrm{~L}_{2}$ & $64.67 \mathrm{de}$ & $61.67 \mathrm{~cd}$ & $22.67 \mathrm{~cd}$ & $20.33 b c$ & $65.30 \mathrm{de}$ & $64.20 c-e$ & $24.96 \mathrm{c}$ & $22.83 \mathrm{c}$ & $64.98 \mathrm{f}$ & $62.93 \mathrm{de}$ & $23.81 \mathrm{~b}$ & $21.58 \mathrm{~b}$ \\
\hline $\mathrm{M}_{1} \mathrm{~L}_{3}$ & $65.33 \mathrm{~b}-\mathrm{e}$ & $62.33 \mathrm{~cd}$ & $23.00 \mathrm{~cd}$ & $20.33 b c$ & $67.10 c-\mathrm{e}$ & $64.86 c-e$ & $25.36 \mathrm{c}$ & $23.16 \mathrm{c}$ & $66.22 \mathrm{ef}$ & 63.60de & $24.18 \mathrm{~b}$ & $21.75 b$ \\
\hline $\mathrm{M}_{1} \mathrm{~L}_{4}$ & $65.67 \mathrm{~b}-\mathrm{e}$ & $62.67 \mathrm{~cd}$ & $23.00 \mathrm{~cd}$ & $20.67 a-c$ & $67.24 c-e$ & 63.86de & $25.03 \mathrm{c}$ & $22.83 \mathrm{c}$ & $66.45 \mathrm{~d}-\mathrm{f}$ & $63.27 \mathrm{de}$ & $24.02 \mathrm{~b}$ & $21.75 b$ \\
\hline $\mathrm{M}_{1} \mathrm{~L}_{5}$ & $65.93 a-d$ & $63.00 \mathrm{~cd}$ & $23.33 b-d$ & $21.00 \mathrm{a}-\mathrm{c}$ & $67.27 \mathrm{c}-\mathrm{e}$ & $64.53 c-e$ & $25.68 \mathrm{c}$ & $23.50 \mathrm{c}$ & $66.60 d-f$ & $63.77 \mathrm{de}$ & $24.51 \mathrm{~b}$ & $22.25 b$ \\
\hline $\mathrm{M}_{2} \mathrm{~L}_{1}$ & 69.63a-e & $68.00 \mathrm{a}$ & $23.33 d-d$ & $22.00 \mathrm{ab}$ & $72.82 \mathrm{ab}$ & $67.25 \mathrm{c}$ & $25.60 \mathrm{c}$ & $23.41 \mathrm{c}$ & $71.23 \mathrm{a}-\mathrm{c}$ & $67.62 b$ & $24.47 \mathrm{~b}$ & $22.70 \mathrm{~b}$ \\
\hline $\mathrm{M}_{2} \mathrm{~L}_{2}$ & $67.00 \mathrm{a}-\mathrm{e}$ & $64.67 \mathrm{bc}$ & $23.33 b-d$ & $20.67 a-c$ & $69.48 b-d$ & $70.23 b$ & $25.60 \mathrm{c}$ & $23.41 \mathrm{c}$ & $68.24 b-f$ & $67.45 b c$ & $24.47 \mathrm{~b}$ & $22.04 \mathrm{~b}$ \\
\hline $\mathrm{M}_{2} \mathrm{~L}_{3}$ & 69.00a-e & $67.67 \mathrm{a}$ & $24.00 \mathrm{a}-\mathrm{c}$ & $21.33 a-c$ & $70.38 b c$ & $70.31 \mathrm{~b}$ & $26.27 b c$ & $24.07 b c$ & 69.69a-e & $68.99 \mathrm{ab}$ & $25.13 b$ & $22.70 \mathrm{~b}$ \\
\hline $\mathrm{M}_{2} \mathrm{~L}_{4}$ & $69.17 \mathrm{a}-\mathrm{e}$ & $67.83 \mathrm{a}$ & $24.00 \mathrm{a}-\mathrm{c}$ & $21.67 \mathrm{ab}$ & 72.64ab & $71.25 \mathrm{bab}$ & $26.27 b c$ & $24.07 b c$ & $70.90 \mathrm{a}-\mathrm{d}$ & 69.54ab & $25.13 b$ & $22.87 \mathrm{~b}$ \\
\hline $\mathrm{M}_{2} \mathrm{~L}_{5}$ & 69.52a-e & $67.90 \mathrm{a}$ & $24.00 \mathrm{a}-\mathrm{c}$ & $22.00 \mathrm{ab}$ & $72.75 \mathrm{ab}$ & 70.91ab & $26.27 b c$ & $24.07 b c$ & $71.14 a-c$ & 69.41ab & $25.14 b$ & $23.04 b$ \\
\hline $\mathrm{M}_{3} \mathrm{~L}_{1}$ & $72.00 \mathrm{a}$ & $69.67 \mathrm{a}$ & $26.00 \mathrm{a}$ & $22.00 \mathrm{ab}$ & $75.84 a$ & $73.60 \mathrm{a}$ & $27.65 \mathrm{ab}$ & $25.42 \mathrm{ab}$ & $73.92 \mathrm{a}$ & $71.63 a$ & $26.82 \mathrm{a}$ & $23.71 \mathrm{~b}$ \\
\hline $\mathrm{M}_{3} \mathrm{~L}_{2}$ & $70.33 a-d$ & 67.00ab & $24.67 \mathrm{a}-\mathrm{c}$ & $22.33 \mathrm{ab}$ & 73.54ab & $72.26 \mathrm{ab}$ & $27.94 \mathrm{ab}$ & $25.75 \mathrm{ab}$ & 71.94ab & $69.63 \mathrm{ab}$ & $26.30 \mathrm{a}$ & $24.04 \mathrm{a}$ \\
\hline $\mathrm{M}_{3} \mathrm{~L}_{3}$ & $71.00 \mathrm{a}-\mathrm{c}$ & $69.00 \mathrm{a}$ & $25.33 a-c$ & $23.00 \mathrm{a}$ & $75.16 \mathrm{a}$ & 72.93ab & $28.61 \mathrm{a}$ & $26.42 \mathrm{a}$ & $73.08 \mathrm{a}$ & $70.97 a$ & $26.97 \mathrm{a}$ & 24.71a \\
\hline $\mathrm{M}_{3} \mathrm{~L}_{4}$ & 71.33ab & $69.00 \mathrm{a}$ & $25.67 a b$ & $22.67 \mathrm{ab}$ & $75.50 \mathrm{a}$ & 73.26ab & $28.28 \mathrm{a}$ & $26.08 \mathrm{a}$ & $73.42 \mathrm{a}$ & $71.13 \mathrm{a}$ & $26.97 \mathrm{a}$ & $24.38 \mathrm{a}$ \\
\hline $\mathrm{M}_{3} \mathrm{~L}_{5}$ & 71.56ab & $69.08 \mathrm{a}$ & $26.00 \mathrm{a}$ & $22.67 \mathrm{ab}$ & $75.59 a$ & 72.93ab & $28.28 \mathrm{a}$ & $26.08 \mathrm{a}$ & $73.58 \mathrm{a}$ & $71.00 \mathrm{a}$ & $27.14 a$ & $24.38 \mathrm{a}$ \\
\hline $\mathrm{C}_{1}$ & $63.67 \mathrm{e}$ & $61.37 \mathrm{~d}$ & $21.33 \mathrm{~d}$ & $19.00 \mathrm{c}$ & $63.89 \mathrm{e}$ & $61.82 \mathrm{e}$ & $21.48 \mathrm{~d}$ & $19.53 \mathrm{~d}$ & $63.78 \mathrm{f}$ & $61.59 \mathrm{e}$ & $21.41 \mathrm{c}$ & $19.27 \mathrm{c}$ \\
\hline S.Em. \pm & 1.75 & 0.97 & 0.784 & 0.751 & 1.38 & 0.978 & 0.581 & 0.593 & 1.39 & 0.933 & 0.402 & 0.381 \\
\hline
\end{tabular}

Note: EC- Enriched compost; C- Compost; VC - Vermicompost ; $\mathrm{M}_{1-}$ RDF-80:40:40 NPK kg ha ${ }^{-1}+\mathrm{FYM} @ 5 \mathrm{t} \mathrm{ha}^{-1} ; \mathrm{M}_{2}-\mathrm{EC}(1 / 3)+\mathrm{VC}(1 / 3)+\mathrm{GLM}(1 / 3)$ equi.to RDN ; $\mathrm{M}_{3}$ - EC (1/3)+ VC(1/3) + GLM (1/3) equi.to RDF; $\mathrm{L}_{1-}$ Panchagavvy @ 5\%; $\mathrm{L}_{2}$-Bio-digester @ 20\% ; $\mathrm{L}_{3}$ - Cow urine @ 10\%; $\mathrm{L}_{4}$ - Vermiwash @ $20 \% ; \mathrm{L}_{5}$ - borax @ 0.2\% + $\mathrm{MgSO}_{4} @ 1 \% ; \mathrm{C}_{1}-\mathrm{RDF}-80: 40: 40 \mathrm{NPK} \mathrm{kg}+\mathrm{FYM} @ 5 \mathrm{t} \mathrm{ha}^{-1}$ 
Table.2 Actinomycetes (cfuX10 / g of soil) and $\mathrm{N}_{2}$ ( $\mathrm{cfuX1} 10^{3} / \mathrm{g}$ of soil) fixers population observed in cotton soil as influenced by organic manures, GLM, liquid organic manures and micronutrients

\begin{tabular}{|c|c|c|c|c|c|c|c|c|c|c|c|c|}
\hline \multirow[t]{2}{*}{ Treatment } & \multicolumn{4}{|c|}{2010} & \multicolumn{4}{|c|}{2011} & \multicolumn{4}{|c|}{ Pooled } \\
\hline & $\begin{array}{l}\text { Actinomycetes } \\
\text { at } 60 \text { DAS }\end{array}$ & $\begin{array}{l}\text { Actinomycetes } \\
\text { at } 90 \text { DAS }\end{array}$ & $\begin{array}{c}\mathbf{N}_{2} \text { fixers } \\
\text { at } 60 \\
\text { DAS }\end{array}$ & $\begin{array}{c}\mathrm{N}_{2} \\
\text { fixers at } \\
90 \text { DAS }\end{array}$ & $\begin{array}{l}\text { Actinomycetes } \\
\text { at } 60 \text { DAS }\end{array}$ & $\begin{array}{l}\text { Actinomycetes } \\
\text { at } 90 \text { DAS }\end{array}$ & $\begin{array}{l}\mathrm{N}_{2} \text { fixers at } \\
\text { 60 DAS }\end{array}$ & $\begin{array}{c}\mathrm{N}_{2} \text { fixers } \\
\text { at } 90 \text { DAS }\end{array}$ & $\begin{array}{l}\text { Actinomycetes } \\
\text { at } 60 \text { DAS }\end{array}$ & $\begin{array}{l}\text { Actinomycetes } \\
\text { at } 90 \text { DAS }\end{array}$ & $\begin{array}{c}\mathrm{N}_{2} \text { fixers at } \\
60 \text { DAS }\end{array}$ & $\begin{array}{c}\mathrm{N}_{2} \text { fixers at } \\
90 \text { DAS }\end{array}$ \\
\hline \multicolumn{13}{|c|}{ Organic Manure (M) } \\
\hline $\mathrm{M}_{1}$ & $34.40 \mathrm{c}$ & $32.13 \mathrm{c}$ & $23.93 \mathrm{c}$ & $22.33 c$ & $36.83 \mathrm{c}$ & $34.68 \mathrm{c}$ & $25.79 \mathrm{c}$ & $23.75 \mathrm{c}$ & $35.62 \mathrm{c}$ & $33.41 \mathrm{c}$ & $24.86 \mathrm{c}$ & $23.04 \mathrm{c}$ \\
\hline $\mathrm{M}_{2}$ & $36.67 \mathrm{~b}$ & $34.27 \mathrm{~b}$ & $27.60 \mathrm{~b}$ & $25.00 \mathrm{~b}$ & $38.78 \mathrm{~b}$ & $36.58 \mathrm{~b}$ & $30.81 \mathrm{~b}$ & $28.46 \mathrm{~b}$ & $37.72 b$ & $35.43 \mathrm{~b}$ & $29.21 \mathrm{~b}$ & $26.73 b$ \\
\hline $\mathrm{M}_{3}$ & $38.27 \mathrm{a}$ & $35.67 \mathrm{a}$ & $32.00 \mathrm{a}$ & $27.47 \mathrm{a}$ & $41.03 \mathrm{a}$ & $38.73 a$ & $34.31 \mathrm{a}$ & $31.57 \mathrm{a}$ & $39.65 a$ & $37.20 \mathrm{a}$ & $33.15 \mathrm{a}$ & $29.52 \mathrm{a}$ \\
\hline S.Em. \pm & 0.239 & 0.154 & 0.539 & 0.353 & 0.182 & 0.136 & 0.511 & 0.235 & 0.174 & 0.143 & 0.335 & 0.294 \\
\hline \multicolumn{13}{|c|}{ Foliar spray of liquid manures + micronutrients (L) } \\
\hline $\mathrm{L}_{1}$ & $36.67 \mathrm{a}$ & $34.44 \mathrm{a}$ & $30.56 \mathrm{a}$ & $28.78 \mathrm{a}$ & $39.02 \mathrm{a}$ & $36.73 \mathrm{ab}$ & $34.06 \mathrm{a}$ & $32.07 \mathrm{a}$ & $37.85 \mathrm{a}$ & $35.59 \mathrm{ab}$ & $32.31 \mathrm{a}$ & $30.42 \mathrm{a}$ \\
\hline $\mathrm{L}_{2}$ & $35.89 \mathrm{a}$ & $33.33 b$ & $24.56 b$ & $21.67 \mathrm{c}$ & $38.49 \mathrm{a}$ & $35.61 \mathrm{~b}$ & $26.72 \mathrm{c}$ & $23.92 \mathrm{c}$ & $37.19 \mathrm{a}$ & $34.47 \mathrm{~b}$ & $25.64 \mathrm{c}$ & $22.79 \mathrm{c}$ \\
\hline $\mathrm{L}_{3}$ & $36.11 \mathrm{a}$ & $33.78 \mathrm{ab}$ & $25.56 \mathrm{~b}$ & $22.33 \mathrm{c}$ & $38.78 \mathrm{a}$ & $36.73 \mathrm{ab}$ & $27.90 \mathrm{c}$ & $25.19 \mathrm{c}$ & $37.45 \mathrm{a}$ & $35.25 \mathrm{ab}$ & $26.73 c$ & $23.76 \mathrm{c}$ \\
\hline $\mathrm{L}_{4}$ & $37.11 \mathrm{a}$ & $34.44 \mathrm{a}$ & $28.56 \mathrm{a}$ & $25.33 b$ & $39.00 \mathrm{a}$ & $37.29 \mathrm{a}$ & $30.81 \mathrm{~b}$ & $28.62 b$ & $38.06 \mathrm{a}$ & $35.87 \mathrm{a}$ & $29.68 b$ & $26.98 b$ \\
\hline $\mathrm{L}_{5}$ & $36.44 a$ & $34.11 \mathrm{ab}$ & $30.00 \mathrm{a}$ & $26.56 b$ & $39.11 \mathrm{a}$ & $36.95 \mathrm{ab}$ & $32.03 \mathrm{~b}$ & $29.85 b$ & $37.78 \mathrm{a}$ & $35.53 \mathrm{ab}$ & $31.02 \mathrm{ab}$ & $28.20 \mathrm{~b}$ \\
\hline S.Em. \pm & 0.45 & 0.329 & 0.779 & 0.729 & 0.385 & 0.438 & 0.625 & 0.761 & 0.278 & 0.37 & 0.504 & 0.732 \\
\hline \multicolumn{13}{|c|}{ Interactions (MXL) } \\
\hline $\mathrm{M}_{1} \mathrm{~L}_{1}$ & $34.33 d-f$ & $32.33 \mathrm{~cd}$ & $26.33 d-f$ & $25.00 \mathrm{c}-\mathrm{e}$ & $36.74 d$ & $34.69 f g$ & $28.38 \mathrm{e}-\mathrm{g}$ & $26.78 d-f$ & $35.54 \mathrm{e}$ & $33.51 \mathrm{~d}$ & $27.36 \mathrm{ef}$ & $25.89 \mathrm{~d}-\mathrm{f}$ \\
\hline $\mathrm{M}_{1} \mathrm{~L}_{2}$ & $33.67 \mathrm{ef}$ & $32.00 \mathrm{~cd}$ & 20.67hi & $20.00 \mathrm{gh}$ & $36.77 \mathrm{~d}$ & $34.19 \mathrm{~g}$ & $22.77 \mathrm{i}$ & $20.73 \mathrm{hi}$ & $35.22 \mathrm{e}$ & $33.09 \mathrm{~d}$ & $21.72 \mathrm{~g}$ & 20.36hi \\
\hline $\mathrm{M}_{1} \mathrm{~L}_{3}$ & $34.33 \mathrm{~d}-\mathrm{f}$ & $32.00 \mathrm{~cd}$ & $21.33 \mathrm{~g}-\mathrm{i}$ & $20.67 f-h$ & $36.85 \mathrm{~d}$ & $34.80 \mathrm{fg}$ & 23.89hi & $21.70 \mathrm{~g}-\mathrm{i}$ & $35.59 \mathrm{e}$ & $33.40 \mathrm{~d}$ & $22.61 \mathrm{~g}$ & $21.19 \mathrm{~g}-\mathrm{i}$ \\
\hline $\mathrm{M}_{1} \mathrm{~L}_{4}$ & $35.00 c-f$ & $32.00 \mathrm{~cd}$ & $25.33 \mathrm{~d}-\mathrm{g}$ & $22.33 f-g$ & $36.74 d$ & $34.69 \mathrm{fg}$ & $26.30 \mathrm{gh}$ & $24.11 \mathrm{f}-\mathrm{h}$ & $35.87 \mathrm{de}$ & $33.34 d$ & $25.82 \mathrm{f}$ & $23.22 \mathrm{e}-\mathrm{h}$ \\
\hline $\mathrm{M}_{1} \mathrm{~L}_{5}$ & $34.67 d-f$ & $32.33 \mathrm{~cd}$ & 26.00d-f & $23.67 d-g$ & $37.07 \mathrm{~d}$ & $35.02 \mathrm{fg}$ & $27.63 \mathrm{fg}$ & $25.45 \mathrm{e}-\mathrm{g}$ & $35.87 \mathrm{de}$ & $33.68 \mathrm{~d}$ & $26.82 \mathrm{f}$ & $24.56 \mathrm{e}-\mathrm{g}$ \\
\hline $\mathrm{M}_{2} \mathrm{~L}_{1}$ & $36.67 a-d$ & $35.00 \mathrm{ab}$ & $31.33 \mathrm{a}-\mathrm{c}$ & $29.00 \mathrm{ab}$ & $39.25 b c$ & $36.88 \mathrm{~b}-\mathrm{f}$ & $34.84 \mathrm{bc}$ & $32.65 b c$ & $37.96 b c$ & $35.94 b c$ & $33.09 b c$ & $30.83 b c$ \\
\hline $\mathrm{M}_{2} \mathrm{~L}_{2}$ & $36.67 a-d$ & $33.33 b c$ & $23.67 \mathrm{f}-\mathrm{i}$ & $21.67 \mathrm{e}-\mathrm{g}$ & $38.35 \mathrm{~cd}$ & $35.19 \mathrm{e}-\mathrm{g}$ & $27.27 \mathrm{fg}$ & $24.28 \mathrm{f}-\mathrm{h}$ & $37.51 \mathrm{c}$ & $34.26 \mathrm{~cd}$ & $25.47 \mathrm{f}$ & $22.98 \mathrm{f}-\mathrm{h}$ \\
\hline $\mathrm{M}_{2} \mathrm{~L}_{3}$ & $36.00 \mathrm{~b}-\mathrm{e}$ & $33.67 b c$ & $24.33 \mathrm{e}-\mathrm{h}$ & $22.00 \mathrm{e}-\mathrm{g}$ & $38.47 \mathrm{~cd}$ & $36.42 \mathrm{c}-\mathrm{g}$ & $27.95 \mathrm{e}$ & $25.72 \mathrm{e}-\mathrm{g}$ & $37.24 \mathrm{~cd}$ & $35.04 \mathrm{~cd}$ & $26.14 f$ & $23.86 \mathrm{e}-\mathrm{h}$ \\
\hline $\mathrm{M}_{2} \mathrm{~L}_{4}$ & $38.00 \mathrm{ab}$ & $35.67 \mathrm{a}$ & $28.00 \mathrm{c}-\mathrm{e}$ & $25.33 \mathrm{~b}-\mathrm{e}$ & $39.25 b c$ & $38.21 \mathrm{a}-\mathrm{d}$ & $31.17 \mathrm{de}$ & $28.98 \mathrm{c}-\mathrm{e}$ & $38.63 a-c$ & $36.94 \mathrm{ab}$ & 29.59de & $27.16 \mathrm{c}-\mathrm{e}$ \\
\hline $\mathrm{M}_{2} \mathrm{~L}_{5}$ & $36.00 \mathrm{~b}-\mathrm{e}$ & $33.67 b c$ & $30.67 a-c$ & $27.00 \mathrm{~b}-\mathrm{d}$ & $38.58 \mathrm{~cd}$ & $36.21 d-g$ & $32.84 b c$ & $30.65 b-d$ & $37.29 \mathrm{~cd}$ & $34.94 \mathrm{~cd}$ & $31.75 \mathrm{~cd}$ & $28.83 b-d$ \\
\hline $\mathrm{M}_{3} \mathrm{~L}_{1}$ & $39.00 \mathrm{a}$ & $36.00 \mathrm{a}$ & $34.00 \mathrm{a}$ & $32.33 \mathrm{a}$ & 41.08ab & $38.63 a-c$ & $38.96 a$ & $36.77 \mathrm{a}$ & $40.04 a$ & $37.32 \mathrm{ab}$ & $36.48 \mathrm{a}$ & $34.55 \mathrm{a}$ \\
\hline $\mathrm{M}_{3} \mathrm{~L}_{2}$ & $37.33 b-c$ & $34.67 \mathrm{ab}$ & $29.33 b-d$ & $23.33 \mathrm{~d}-\mathrm{g}$ & $40.35 a-c$ & 37.46a-e & $30.14 d-f$ & $26.74 d-f$ & $38.84 a-c$ & 36.06a-c & 29.74de & $25.04 d-g$ \\
\hline $\mathrm{M}_{3} \mathrm{~L}_{3}$ & $38.00 \mathrm{ab}$ & $35.67 \mathrm{a}$ & $31.00 \mathrm{a}-\mathrm{c}$ & $24.33 \mathrm{~d}-\mathrm{f}$ & $41.01 \mathrm{ab}$ & $38.96 \mathrm{ab}$ & $31.85 \mathrm{~cd}$ & $28.14 d-f$ & $39.51 \mathrm{ab}$ & $37.32 \mathrm{ab}$ & $31.42 \mathrm{~cd}$ & $26.24 d-f$ \\
\hline $\mathrm{M}_{3} \mathrm{~L}_{4}$ & 38.33ab & $35.67 \mathrm{a}$ & $32.33 \mathrm{ab}$ & $28.33 b c$ & $41.01 \mathrm{ab}$ & $38.96 a b$ & $34.96 b c$ & $32.77 b c$ & $39.67 \mathrm{a}$ & 37.32ab & $33.65 b c$ & $30.55 b c$ \\
\hline $\mathrm{M}_{3} \mathrm{~L}_{5}$ & $38.67 \mathrm{a}$ & $36.33 a$ & $33.33 \mathrm{ab}$ & $29.00 \mathrm{ab}$ & $41.68 \mathrm{a}$ & $39.63 a$ & $35.63 b$ & $33.44 \mathrm{ab}$ & $40.17 \mathrm{a}$ & $37.98 \mathrm{a}$ & $34.48 \mathrm{ab}$ & $31.22 \mathrm{ab}$ \\
\hline $\mathrm{C}_{1}$ & $33.33 \mathrm{f}$ & $31.00 \mathrm{~d}$ & $20.00 \mathrm{i}$ & $17.67 \mathrm{~h}$ & $33.60 \mathrm{e}$ & $31.48 \mathrm{~h}$ & $21.16 \mathrm{i}$ & $18.99 \mathrm{i}$ & $33.47 \mathrm{f}$ & $31.24 \mathrm{e}$ & $20.58 \mathrm{~g}$ & $18.33 \mathrm{i}$ \\
\hline S.Em. \pm & 0.77 & 0.539 & 1.29 & 1.17 & 0.658 & 0.728 & 1.057 & 1.318 & 0.511 & 0.59 & 0.83 & 1.21 \\
\hline
\end{tabular}

Note: EC- Enriched compost; C- Compost; VC - Vermicompost ; $\mathrm{M}_{1-} \mathrm{RDF}-80: 40: 40 \mathrm{NPK} \mathrm{kg} \mathrm{ha}{ }^{-1}+\mathrm{FYM} @ 5 \mathrm{t} \mathrm{ha}^{-1} ; \mathrm{M}_{2}$ - EC (1/3)+ VC(1/3) + GLM (1/3) equi.to RDN; $\mathrm{M}_{3}$ - EC (1/3)+VC(1/3) + GLM (1/3) equi.to RDF; L $\mathrm{L}_{1}$ Panchagavvy @ 5\%; L $\mathrm{L}_{2}$-Bio-digester @ 20\%; $\mathrm{L}_{3}$ - Cow urine @ 10\%; $\mathrm{L}_{4}$ - Vermiwash @ $20 \% ; \mathrm{L}_{5}$ - borax @ 0.2\%+ $\mathrm{MgSO}_{4} @ 1 \% ; \mathrm{C}_{1}-\mathrm{RDF}-80: 40: 40 \mathrm{NPK} \mathrm{kg}+\mathrm{FYM} @ 5 \mathrm{tha}^{-1}$ 
Table.3 PSM (cfuX10 $/ \mathrm{g}$ of soil) population and dehydrogenase activity ( $\mu \mathrm{g}$ TPF /g of soil / day) observed in cotton soil as influenced by organic manures, GLM, liquid organic manures and micronutrients

\begin{tabular}{|c|c|c|c|c|c|c|c|c|c|c|c|c|}
\hline \multirow[t]{2}{*}{ Treatment } & \multicolumn{4}{|c|}{2010} & \multicolumn{4}{|c|}{2011} & \multicolumn{4}{|c|}{ Pooled } \\
\hline & $\begin{array}{c}\text { PSM } \\
\text { at } 60 \text { DAS }\end{array}$ & PSM at 90DAS & $\begin{array}{l}\text { Dehydrogenase } \\
\text { at } 60 \text { DAS }\end{array}$ & $\begin{array}{l}\text { Dehydrogen } \\
\text { ase } \\
\text { at } 90 \text { DAS }\end{array}$ & $\begin{array}{l}\text { PSM at } \\
\text { 60 DAS }\end{array}$ & $\begin{array}{l}\text { PSM at } \\
\text { 90 DAS }\end{array}$ & $\begin{array}{l}\text { Dehydrogenase } \\
\text { at } 60 \text { DAS }\end{array}$ & $\begin{array}{l}\text { Dehydrogenase } \\
\text { at } 90 \text { DAS }\end{array}$ & $\begin{array}{l}\text { PSM at } \\
\text { 60 DAS }\end{array}$ & $\begin{array}{l}\text { PSM at } \\
\text { 90 DAS }\end{array}$ & $\begin{array}{l}\text { Dehydrogenase } \\
\text { at } 60 \text { DAS }\end{array}$ & $\begin{array}{c}\text { Dehydrogenase } \\
\text { at } 90 \text { DAS }\end{array}$ \\
\hline \multicolumn{13}{|c|}{ Organic Manure (M) } \\
\hline $\mathrm{M}_{1}$ & $16.73 \mathrm{c}$ & $14.82 \mathrm{c}$ & $8.51 \mathrm{c}$ & $7.09 \mathrm{~b}$ & $17.77 \mathrm{c}$ & $15.81 \mathrm{c}$ & $10.14 \mathrm{c}$ & $8.42 \mathrm{c}$ & $17.25 \mathrm{c}$ & $15.31 \mathrm{c}$ & $9.33 \mathrm{c}$ & $7.76 \mathrm{c}$ \\
\hline $\mathrm{M}_{2}$ & $20.80 \mathrm{~b}$ & $18.47 \mathrm{~b}$ & $9.48 \mathrm{~b}$ & $8.02 \mathrm{a}$ & $23.20 \mathrm{~b}$ & $21.42 \mathrm{~b}$ & $12.54 \mathrm{~b}$ & $10.75 b$ & $22.00 \mathrm{~b}$ & $19.94 \mathrm{~b}$ & $11.01 \mathrm{~b}$ & $9.38 \mathrm{~b}$ \\
\hline $\mathrm{M}_{3}$ & $24.67 \mathrm{a}$ & $22.73 a$ & $9.85 \mathrm{a}$ & $8.22 \mathrm{a}$ & $27.64 a$ & $25.89 \mathrm{a}$ & $14.13 \mathrm{a}$ & $12.32 \mathrm{a}$ & $26.15 \mathrm{a}$ & $24.31 \mathrm{a}$ & $11.99 a$ & $10.27 \mathrm{a}$ \\
\hline S.Em. \pm & 0.478 & 0.499 & 0.0935 & 0.129 & 0.202 & 0.271 & 0.149 & 0.171 & 0.245 & 0.421 & 0.029 & 0.072 \\
\hline \multicolumn{13}{|c|}{ Foliar spray of liquid manures + micronutrients $(\mathrm{L})$} \\
\hline $\mathrm{L}_{1}$ & $22.89 a$ & $20.56 a$ & $9.69 \mathrm{a}$ & $8.27 \mathrm{a}$ & $25.30 \mathrm{a}$ & $23.26 \mathrm{a}$ & $12.71 \mathrm{a}$ & $10.97 \mathrm{a}$ & $24.09 a$ & $21.91 \mathrm{a}$ & $11.20 \mathrm{a}$ & $9.62 \mathrm{a}$ \\
\hline $\mathrm{L}_{2}$ & $18.89 \mathrm{~d}$ & $17.78 \mathrm{~cd}$ & $8.87 \mathrm{~b}$ & $7.04 b$ & $20.20 c$ & $19.22 \mathrm{c}$ & $11.68 \mathrm{c}$ & $9.84 \mathrm{c}$ & $19.55 \mathrm{~d}$ & $18.50 \mathrm{~cd}$ & $10.27 b$ & $8.44 \mathrm{c}$ \\
\hline $\mathrm{L}_{3}$ & $19.33 \mathrm{~cd}$ & $16.89 \mathrm{~d}$ & $8.99 \mathrm{~b}$ & 7.57ab & $21.58 \mathrm{c}$ & $19.53 \mathrm{c}$ & $12.03 \mathrm{bc}$ & $10.27 \mathrm{bc}$ & $20.46 c$ & $18.21 \mathrm{ab}$ & $10.51 \mathrm{~b}$ & $8.92 b$ \\
\hline $\mathrm{L}_{4}$ & $20.89 \mathrm{bc}$ & $18.67 \mathrm{bc}$ & $9.35 \mathrm{a}$ & $7.92 \mathrm{a}$ & $23.19 b$ & $21.14 b$ & $12.38 \mathrm{ab}$ & $10.62 \mathrm{ab}$ & $22.04 \mathrm{~b}$ & 19.91ab & $10.86 \mathrm{a}$ & $9.27 \mathrm{ab}$ \\
\hline $\mathrm{L}_{5}$ & $21.67 \mathrm{ab}$ & $19.47 \mathrm{ab}$ & $9.51 \mathrm{a}$ & $8.09 \mathrm{a}$ & $24.08 \mathrm{ab}$ & $22.03 \mathrm{ab}$ & $12.56 \mathrm{ab}$ & $10.79 \mathrm{ab}$ & $22.87 \mathrm{~b}$ & $20.75 \mathrm{ab}$ & $11.03 \mathrm{a}$ & $9.44 \mathrm{a}$ \\
\hline S.Em. \pm & 0.482 & 0.497 & 0.119 & 0.245 & 0.521 & 0.542 & 0.189 & 0.202 & 0.289 & 0.413 & 0.111 & 0.159 \\
\hline \multicolumn{13}{|c|}{ Interactions (MXL) } \\
\hline $\mathrm{M}_{1} \mathrm{~L}_{1}$ & $18.67 d-g$ & $16.33 \mathrm{ef}$ & $8.89 \mathrm{e}-\mathrm{g}$ & $7.47 \mathrm{~b}-\mathrm{g}$ & $19.93 f-h$ & $17.88 \mathrm{ef}$ & $10.59 \mathrm{f}$ & $8.83 \mathrm{f}$ & $19.30 \mathrm{gh}$ & $17.11 \mathrm{~g}-\mathrm{i}$ & $9.74 \mathrm{f}$ & $8.15 \mathrm{fg}$ \\
\hline $\mathrm{M}_{1} \mathrm{~L}_{2}$ & $15.33 \mathrm{~g}$ & $13.33 \mathrm{~g}$ & $8.17 \mathrm{~h}$ & $6.77 \mathrm{~g}$ & $16.12 \mathrm{i}$ & $14.48 \mathrm{gh}$ & $9.50 \mathrm{gh}$ & $7.96 f g$ & $15.73 \mathrm{j}$ & $13.91 \mathrm{jk}$ & $8.84 \mathrm{~h}$ & $7.37 \mathrm{gh}$ \\
\hline $\mathrm{M}_{1} \mathrm{~L}_{3}$ & $15.67 \mathrm{~g}$ & $14.33 \mathrm{fg}$ & $8.22 \mathrm{~h}$ & $6.80 \mathrm{fg}$ & $16.62 \mathrm{i}$ & $14.57 \mathrm{gh}$ & $9.92 \mathrm{f}-\mathrm{h}$ & $8.16 \mathrm{f}$ & $16.14 \mathrm{j}$ & $14.45 \mathrm{jk}$ & $9.07 \mathrm{gh}$ & $7.48 \mathrm{gh}$ \\
\hline $\mathrm{M}_{1} \mathrm{~L}_{4}$ & $16.67 \mathrm{fg}$ & $14.67 \mathrm{fg}$ & $8.56 \mathrm{gh}$ & $7.13 \mathrm{~d}-\mathrm{g}$ & 17.59hi & $15.55 \mathrm{f}-\mathrm{h}$ & $10.25 \mathrm{f}-\mathrm{g}$ & $8.50 \mathrm{f}$ & $17.13 \mathrm{ij}$ & $15.11 \mathrm{i}-\mathrm{k}$ & $9.40 \mathrm{fg}$ & $7.82 \mathrm{~g}$ \\
\hline $\mathrm{M}_{1} \mathrm{~L}_{5}$ & $17.33 \mathrm{fg}$ & $15.42 \mathrm{fg}$ & $8.72 \mathrm{f}-\mathrm{h}$ & $7.30 \mathrm{c}-\mathrm{g}$ & $18.59 \mathrm{~g}-\mathrm{i}$ & $16.55 f g$ & $10.44 f-g$ & $8.66 \mathrm{f}$ & 17.96hi & $15.98 \mathrm{~h}-\mathrm{j}$ & $9.58 \mathrm{fg}$ & $7.98 \mathrm{fg}$ \\
\hline $\mathrm{M}_{2} \mathrm{~L}_{1}$ & $22.33 \mathrm{e}-\mathrm{g}$ & $20.00 \mathrm{~cd}$ & $9.86 a-d$ & $8.43 a-d$ & $24.97 \mathrm{~cd}$ & $22.93 \mathrm{~cd}$ & $12.97 \mathrm{~b}-\mathrm{d}$ & $11.21 \mathrm{~cd}$ & $23.65 \mathrm{~cd}$ & $21.47 \mathrm{de}$ & $11.42 \mathrm{c}$ & $9.82 b-d$ \\
\hline $\mathrm{M}_{2} \mathrm{~L}_{2}$ & $19.33 c-f$ & $18.33 \mathrm{de}$ & $9.05 \mathrm{e}-\mathrm{g}$ & $7.43 b-g$ & $20.94 \mathrm{e}-\mathrm{g}$ & $20.22 \mathrm{de}$ & $11.88 \mathrm{e}$ & $9.98 \mathrm{e}$ & $20.14 f g$ & $19.28 \mathrm{e}-\mathrm{g}$ & $10.47 \mathrm{e}$ & $8.71 \mathrm{ef}$ \\
\hline $\mathrm{M}_{2} \mathrm{~L}_{3}$ & $20.00 \mathrm{c}-\mathrm{e}$ & $16.33 \mathrm{ef}$ & $9.22 \mathrm{~d}-\mathrm{f}$ & $7.80 \mathrm{a}-\mathrm{g}$ & $22.45 d-f$ & 20.41de & $12.33 \mathrm{de}$ & $10.57 \mathrm{de}$ & $21.23 \mathrm{ef}$ & $18.37 \mathrm{f}-\mathrm{h}$ & $10.78 \mathrm{de}$ & $9.19 \mathrm{de}$ \\
\hline $\mathrm{M}_{2} \mathrm{~L}_{4}$ & $21.00 \mathrm{~cd}$ & $18.67 \mathrm{de}$ & $9.56 \mathrm{~b}-\mathrm{e}$ & $8.13 a-e$ & $23.64 c-e$ & $21.60 \mathrm{~cd}$ & $12.67 \mathrm{c}-\mathrm{e}$ & 10.91de & $22.32 \mathrm{de}$ & $20.13 d-f$ & $11.11 \mathrm{~cd}$ & $9.52 \mathrm{c}-\mathrm{e}$ \\
\hline $\mathrm{M}_{2} \mathrm{~L}_{5}$ & $21.33 \mathrm{~cd}$ & $19.00 \mathrm{c}-\mathrm{e}$ & $9.72 a-d$ & $8.30 \mathrm{a}-\mathrm{d}$ & $23.97 \mathrm{~cd}$ & $21.93 \mathrm{~cd}$ & $12.83 \mathrm{~b}-\mathrm{e}$ & $11.07 \mathrm{c}-\mathrm{e}$ & $22.65 c-e$ & $20.47 d-f$ & $11.28 \mathrm{~cd}$ & $9.69 b-d$ \\
\hline $\mathrm{M}_{3} \mathrm{~L}_{1}$ & $27.67 \mathrm{a}$ & $25.33 \mathrm{a}$ & $10.33 \mathrm{a}$ & $8.90 \mathrm{a}$ & $31.00 \mathrm{a}$ & $28.95 \mathrm{a}$ & $14.56 \mathrm{a}$ & $12.86 \mathrm{a}$ & $29.33 \mathrm{a}$ & $27.14 \mathrm{a}$ & $12.45 \mathrm{a}$ & $10.88 \mathrm{a}$ \\
\hline $\mathrm{M}_{3} \mathrm{~L}_{2}$ & 22 & $21.67 \mathrm{bc}$ & $9.38 \mathrm{c}-\mathrm{f}$ & $6.93 \mathrm{e}-\mathrm{g}$ & $23.54 c-e$ & $22.95 \mathrm{~cd}$ & $13.64 a-c$ & $11.57 b-d$ & $22.77 \mathrm{c}-\mathrm{e}$ & $22.31 \mathrm{~cd}$ & $11.51 \mathrm{c}$ & $9.25 c-e$ \\
\hline $\mathrm{M}_{3} \mathrm{~L}_{3}$ & $22.33 \mathrm{bc}$ & $20.00 \mathrm{~cd}$ & $9.52 \mathrm{~b}-\mathrm{e}$ & $8.10 \mathrm{a}-\mathrm{f}$ & $25.66 c$ & $23.62 c$ & 13.83ab & $12.06 a-c$ & $24.00 \mathrm{c}$ & $21.81 \mathrm{de}$ & $11.68 \mathrm{bc}$ & $10.08 \mathrm{a}-\mathrm{c}$ \\
\hline $\mathrm{M}_{3} \mathrm{~L}_{4}$ & $25.00 \mathrm{ab}$ & $22.67 \mathrm{~b}$ & $9.92 \mathrm{a}-\mathrm{c}$ & $8.50 \mathrm{a}-\mathrm{c}$ & $28.33 b$ & $26.29 \mathrm{~b}$ & $14.22 \mathrm{a}$ & $12.46 \mathrm{ab}$ & $26.67 \mathrm{~b}$ & $24.48 b c$ & $12.07 \mathrm{ab}$ & $10.48 \mathrm{ab}$ \\
\hline $\mathrm{M}_{3} \mathrm{~L}_{5}$ & $26.33 a$ & $24.00 \mathrm{ab}$ & $10.09 \mathrm{ab}$ & $8.67 \mathrm{ab}$ & $29.66 a b$ & $27.62 \mathrm{ab}$ & $14.39 \mathrm{a}$ & $12.63 \mathrm{ab}$ & $28.00 \mathrm{ab}$ & $25.81 \mathrm{ab}$ & $12.24 \mathrm{a}$ & $10.65 \mathrm{a}$ \\
\hline $\mathrm{C}_{1}$ & $16.00 \mathrm{~g}$ & $12.67 \mathrm{~g}$ & $8.20 \mathrm{~h}$ & $6.77 \mathrm{~g}$ & $16.67 \mathrm{i}$ & $13.48 \mathrm{~h}$ & $9.07 \mathrm{~h}$ & $6.96 \mathrm{~g}$ & $16.34 \mathrm{j}$ & $13.08 \mathrm{k}$ & $8.64 \mathrm{~h}$ & $6.87 \mathrm{~h}$ \\
\hline S.Em. \pm & 0.986 & 0.878 & 0.207 & 0.395 & 0.874 & 0.876 & 0.321 & 0.351 & 0.515 & 0.817 & 0.179 & 0.261 \\
\hline
\end{tabular}

Note: EC- Enriched compost; C- Compost; VC - Vermicompost ; $\mathrm{M}_{1-} \mathrm{RDF}-80: 40: 40 \mathrm{NPK} \mathrm{kg} \mathrm{ha}{ }^{-1}+\mathrm{FYM} @ 5 \mathrm{t} \mathrm{ha}^{-1} ; \mathrm{M}_{2}-\mathrm{EC}(1 / 3)+\mathrm{VC}(1 / 3)+\mathrm{GLM}(1 / 3)$ equi.to RDN; $\mathrm{M}_{3}$ - EC (1/3)+ VC(1/3) + GLM (1/3) equi.to RDF; $\mathrm{L}_{1-}$ Panchagavvy @ 5\%; $\mathrm{L}_{2}$-Bio-digester @ 20\% ; $\mathrm{L}_{3}$ - Cow urine @ 10\%; $\mathrm{L}_{4}$ - Vermiwash @ $20 \%$; $\mathrm{L}_{5}$ - borax @ 0.2\% + $\mathrm{MgSO}_{4} @ 1 \% ; \mathrm{C}_{1}-\mathrm{RDF}-80: 40: 40 \mathrm{NPK} \mathrm{kg}+\mathrm{FYM} @ 5 \mathrm{tha}^{-1}$ 
Table.4 Phosphatase activity ( $\mu \mathrm{g}$ pnp TPF /g of soil / hr) and $\mathrm{CO}_{2}$ exchange rate $\left(\mathrm{mg}\right.$ of $\mathrm{CO}_{2} / \mathrm{hr} / 100 \mathrm{~g}$ soil) in cotton soil as influenced by organic manures, GLM, liquid organic manures and micronutrients

\begin{tabular}{|c|c|c|c|c|c|c|c|c|c|c|c|c|}
\hline \multirow[t]{2}{*}{ Treatment } & \multicolumn{4}{|c|}{2010} & \multicolumn{4}{|c|}{2011} & \multicolumn{4}{|c|}{ Pooled } \\
\hline & $\begin{array}{c}\text { Phosphatase } \\
\text { at } 60 \text { DAS }\end{array}$ & $\begin{array}{c}\text { Phosphatase } \\
\text { at } 90 \text { DAS }\end{array}$ & $\begin{array}{c}\mathrm{CO}_{2} \\
\text { exchange at } \\
60 \mathrm{DAS}\end{array}$ & $\begin{array}{c}\mathrm{CO}_{2} \\
\text { exchange } \\
\text { at } 90 \mathrm{DAS}\end{array}$ & $\begin{array}{c}\text { Phosphat } \\
\text { ase at } 60 \\
\text { DAS }\end{array}$ & $\begin{array}{l}\text { Phosphatase } \\
\text { at } 90 \text { DAS }\end{array}$ & $\begin{array}{c}\mathrm{CO}_{2} \\
\text { exchange at } \\
60 \mathrm{DAS}\end{array}$ & $\begin{array}{c}\mathrm{CO}_{2} \\
\text { exchange } \\
\text { at } 90 \mathrm{DAS}\end{array}$ & $\begin{array}{c}\text { Phosphat } \\
\text { ase at } 60 \\
\text { DAS }\end{array}$ & $\begin{array}{l}\text { Phosphatase } \\
\text { at } 90 \text { DAS }\end{array}$ & $\begin{array}{c}\mathrm{CO}_{2} \\
\text { exchange at } \\
60 \mathrm{DAS}\end{array}$ & $\begin{array}{c}\mathrm{CO}_{2} \\
\text { exchange at } \\
90 \mathrm{DAS}\end{array}$ \\
\hline \multicolumn{13}{|c|}{ Organic Manure (M) } \\
\hline $\mathrm{M}_{1}$ & $18.60 \mathrm{c}$ & $17.42 \mathrm{c}$ & $9.34 \mathrm{c}$ & $8.47 \mathrm{c}$ & $20.20 \mathrm{c}$ & $18.71 \mathrm{c}$ & $9.94 c$ & $8.64 c$ & $19.40 \mathrm{c}$ & $18.07 \mathrm{c}$ & $9.64 c$ & $8.55 \mathrm{c}$ \\
\hline $\mathrm{M}_{2}$ & $20.83 b$ & $19.53 b$ & $9.54 b$ & $8.81 \mathrm{~b}$ & $24.35 b$ & $22.68 b$ & $10.13 b$ & $9.23 b$ & $22.59 \mathrm{~b}$ & $21.11 \mathrm{c}$ & $9.84 b$ & $9.02 \mathrm{~b}$ \\
\hline $\mathrm{M}_{3}$ & $22.91 \mathrm{a}$ & $21.78 b$ & 10.29 & $9.34 \mathrm{c}$ & $27.10 \mathrm{a}$ & $25.49 \mathrm{a}$ & $11.12 \mathrm{a}$ & $9.69 a$ & $25.01 \mathrm{a}$ & $23.64 a$ & $10.70 \mathrm{a}$ & $9.51 \mathrm{a}$ \\
\hline S.Em. \pm & 0.22 & 0.33 & 0.142 & 0.140 & 0.18 & 0.18 & 0.014 & 0.13 & 0.120 & 0.123 & 0.07 & 0.08 \\
\hline \multicolumn{13}{|c|}{ Foliar spray of liquid manures + micronutrients $(\mathrm{L})$} \\
\hline $\mathrm{L}_{1}$ & $22.02 \mathrm{a}$ & $20.67 \mathrm{a}$ & $9.94 \mathrm{a}$ & $9.04 \mathrm{a}$ & $25.21 \mathrm{a}$ & $23.32 \mathrm{a}$ & $10.64 \mathrm{a}$ & $9.49 \mathrm{a}$ & $23.61 \mathrm{a}$ & $22.00 \mathrm{a}$ & $10.29 \mathrm{a}$ & $9.26 \mathrm{a}$ \\
\hline $\mathrm{L}_{2}$ & $19.54 \mathrm{c}$ & $18.64 \mathrm{~b}$ & $9.59 \mathrm{a}$ & $8.51 \mathrm{a}$ & $22.67 d$ & $21.35 \mathrm{c}$ & $10.44 \mathrm{c}$ & $8.67 \mathrm{~b}$ & $21.10 \mathrm{e}$ & $20.00 \mathrm{c}$ & $10.01 \mathrm{~b}$ & $8.59 \mathrm{~b}$ \\
\hline $\mathrm{L}_{3}$ & $19.96 \mathrm{c}$ & $18.70 \mathrm{~b}$ & $9.56 \mathrm{a}$ & $8.82 \mathrm{a}$ & $23.39 \mathrm{~cd}$ & $21.62 b c$ & $10.31 d$ & $9.10 \mathrm{ab}$ & $21.68 \mathrm{~d}$ & $20.16 c$ & $9.94 b$ & $8.96 a$ \\
\hline $\mathrm{L}_{4}$ & $20.94 b$ & $19.69 a b$ & $9.93 \mathrm{a}$ & $9.00 \mathrm{a}$ & $23.78 b c$ & $22.35 \mathrm{ab}$ & $10.53 b$ & $9.32 \mathrm{a}$ & $22.36 \mathrm{c}$ & $21.02 \mathrm{~b}$ & $10.23 \mathrm{a}$ & $9.16 \mathrm{a}$ \\
\hline $\mathrm{L}_{5}$ & $21.44 \mathrm{ab}$ & $20.19 a$ & $9.60 \mathrm{a}$ & $9.01 \mathrm{a}$ & $24.37 b$ & $22.85 \mathrm{a}$ & $10.05 \mathrm{e}$ & $9.36 \mathrm{a}$ & $22.90 \mathrm{~b}$ & $21.52 \mathrm{ab}$ & $9.82 b$ & $9.19 \mathrm{a}$ \\
\hline S.Em. \pm & 0.26 & 0.365 & 0.137 & 0.193 & 0.251 & 0.319 & 0.007 & 0.198 & 0.168 & 0.296 & 0.069 & 0.105 \\
\hline \multicolumn{13}{|c|}{ Interactions (MXL) } \\
\hline $\mathrm{M}_{1} \mathrm{~L}_{1}$ & $19.46 f$ & $18.13 d-f$ & $9.58 b-d$ & $8.60 a-d$ & $20.97 \mathrm{e}$ & $19.58 \mathrm{f}$ & $10.38 \mathrm{f}$ & 8.90a-e & $20.21 \mathrm{~h}$ & $18.86 \mathrm{~g}-\mathrm{i}$ & $9.98 \mathrm{de}$ & $8.75 \mathrm{e}-\mathrm{g}$ \\
\hline $\mathrm{M}_{1} \mathrm{~L}_{3}$ & $17.84 \mathrm{~g}-\mathrm{i}$ & $16.53 \mathrm{fg}$ & $9.38 \mathrm{~cd}$ & $8.46 b-d$ & $19.74 \mathrm{ef}$ & $17.98 \mathrm{fg}$ & $9.93 \mathrm{~h}$ & $8.62 \mathrm{c}-\mathrm{e}$ & $18.79 \mathrm{i}$ & $17.26 \mathrm{jk}$ & $9.66 \mathrm{ef}$ & $8.54 f g$ \\
\hline $\mathrm{M}_{1} \mathrm{~L}_{4}$ & $18.84 f-h$ & $17.60 \mathrm{e}-\mathrm{g}$ & $9.64 b-d$ & $8.56 a-d$ & $20.46 \mathrm{e}$ & $19.04 \mathrm{fg}$ & $10.28 \mathrm{~g}$ & $8.80 \mathrm{~b}-\mathrm{e}$ & $19.65 \mathrm{~h}$ & $18.32 \mathrm{ij}$ & $9.96 \mathrm{de}$ & $8.68 \mathrm{e}-\mathrm{g}$ \\
\hline $\mathrm{M}_{1} \mathrm{~L}_{5}$ & $19.16 \mathrm{fg}$ & $17.90 \mathrm{~d}-\mathrm{f}$ & $9.08 \mathrm{~d}$ & $8.55 a-d$ & $20.74 \mathrm{e}$ & $19.34 \mathrm{fg}$ & $9.53 \mathrm{k}$ & 8.66b-e & $19.95 \mathrm{~h}$ & $18.62 \mathrm{~h}-\mathrm{j}$ & $9.31 \mathrm{f}$ & $8.61 \mathrm{e}-\mathrm{g}$ \\
\hline $\mathrm{M}_{2} \mathrm{~L}_{1}$ & $22.41 b c$ & $21.17 \mathrm{a}-\mathrm{c}$ & $9.62 b-d$ & $8.91 \mathrm{a}-\mathrm{d}$ & $26.14 b c$ & $24.05 b-d$ & $10.28 \mathrm{~g}$ & $9.52 \mathrm{a}-\mathrm{c}$ & $24.27 \mathrm{~cd}$ & $22.61 \mathrm{~cd}$ & $9.95 \mathrm{de}$ & $9.22 b-e$ \\
\hline $\mathrm{M}_{2} \mathrm{~L}_{2}$ & $19.65 \mathrm{ef}$ & $18.13 d-f$ & $9.49 b-d$ & $8.56 a-d$ & $22.90 \mathrm{~d}$ & $21.72 \mathrm{e}$ & $10.28 \mathrm{~g}$ & $8.73 b-e$ & $21.28 \mathrm{~g}$ & $19.93 \mathrm{f}-\mathrm{h}$ & $9.88 \mathrm{de}$ & $8.65 \mathrm{e}-\mathrm{g}$ \\
\hline $\mathrm{M}_{2} \mathrm{~L}_{3}$ & $19.71 \mathrm{ef}$ & $18.47 \mathrm{de}$ & $8.99 \mathrm{~d}$ & $8.79 a-d$ & $23.74 d$ & $21.99 \mathrm{e}$ & $9.53 \mathrm{k}$ & $9.14 \mathrm{a}-\mathrm{d}$ & $21.72 \mathrm{fg}$ & $20.23 \mathrm{fg}$ & $9.26 f$ & $8.97 \mathrm{~d}-\mathrm{f}$ \\
\hline $\mathrm{M}_{2} \mathrm{~L}_{4}$ & 20.91de & $19.67 \mathrm{~cd}$ & $10.16 a-c$ & $8.92 \mathrm{a}-\mathrm{d}$ & $23.79 \mathrm{~d}$ & $22.55 \mathrm{de}$ & $10.84 d$ & $9.32 \mathrm{a}-\mathrm{d}$ & $22.35 f$ & $21.11 \mathrm{ef}$ & $10.50 \mathrm{bc}$ & $9.12 c-f$ \\
\hline $\mathrm{M}_{2} \mathrm{~L}_{5}$ & $21.48 \mathrm{~cd}$ & $20.23 b c$ & $9.46 b-d$ & $8.89 a-d$ & $25.20 \mathrm{c}$ & $23.12 \mathrm{c}-\mathrm{e}$ & $9.74 \mathrm{i}$ & $9.46 a-c$ & $23.34 \mathrm{f}$ & $21.68 \mathrm{de}$ & $9.60 \mathrm{ef}$ & $9.17 \mathrm{c}-\mathrm{e}$ \\
\hline $\mathrm{M}_{3} \mathrm{~L}_{1}$ & $24.19 \mathrm{a}$ & $22.70 \mathrm{a}$ & $10.62 \mathrm{a}$ & $9.60 \mathrm{a}$ & $28.53 a$ & $26.34 \mathrm{a}$ & $11.28 \mathrm{~b}$ & $10.04 \mathrm{a}$ & $26.36 \mathrm{a}$ & $24.52 \mathrm{a}$ & $10.95 \mathrm{a}$ & $9.82 \mathrm{a}$ \\
\hline $\mathrm{M}_{3} \mathrm{~L}_{2}$ & $21.29 \mathrm{~cd}$ & $20.87 a-c$ & $10.25 a-c$ & $8.80 a-d$ & $26.01 b c$ & $24.69 a-c$ & $11.48 \mathrm{a}$ & $9.05 a-d$ & $23.65 \mathrm{de}$ & $22.78 b-d$ & $10.86 \mathrm{ab}$ & 8.93d-f \\
\hline $\mathrm{M}_{3} \mathrm{~L}_{3}$ & $22.34 b c$ & $21.10 \mathrm{a}-\mathrm{c}$ & $10.32 \mathrm{ab}$ & $9.20 \mathrm{a}-\mathrm{c}$ & $26.71 \mathrm{~b}$ & $24.89 \mathrm{ab}$ & $11.48 \mathrm{a}$ & $9.53 \mathrm{a}-\mathrm{c}$ & $24.52 c$ & $23.00 \mathrm{~b}-\mathrm{d}$ & $10.90 \mathrm{ab}$ & $9.37 \mathrm{a}-\mathrm{d}$ \\
\hline $\mathrm{M}_{3} \mathrm{~L}_{4}$ & 23.07ab & 21.82ab & $10.00 \mathrm{a}-\mathrm{c}$ & $9.52 \mathrm{ab}$ & $27.09 \mathrm{~b}$ & $25.46 \mathrm{ab}$ & $10.48 \mathrm{e}$ & $9.83 \mathrm{ab}$ & $25.08 b c$ & $23.64 a-c$ & $10.24 \mathrm{~cd}$ & $9.67 a-c$ \\
\hline $\mathrm{M}_{3} \mathrm{~L}_{5}$ & 23.67ab & $22.43 a$ & $10.25 a-c$ & $9.60 \mathrm{a}$ & $27.16 \mathrm{~b}$ & $26.08 \mathrm{a}$ & $10.88 \mathrm{c}$ & $9.97 \mathrm{a}$ & $25.42 b$ & $24.26 a b$ & $10.56 a-c$ & 9.79ab \\
\hline $\mathrm{C}_{1}$ & $17.41 \mathrm{i}$ & $15.83 \mathrm{~g}$ & $8.19 \mathrm{e}$ & $7.81 \mathrm{~d}$ & $17.68 \mathrm{~g}$ & $16.16 \mathrm{~h}$ & 8.431 & $7.84 \mathrm{e}$ & $17.54 j$ & $16.00 \mathrm{k}$ & $8.31 \mathrm{~g}$ & $7.82 \mathrm{~h}$ \\
\hline S.Em. \pm & 0.456 & 0.576 & 0.264 & 0.327 & 0.437 & 0.553 & 0.0091 & 0.345 & 0.278 & 0.476 & 0.133 & 0.183 \\
\hline
\end{tabular}

Note: EC- Enriched compost; C- Compost; VC - Vermicompost ; $\mathrm{M}_{1-} \mathrm{RDF}-80: 40: 40 \mathrm{NPK} \mathrm{kg} \mathrm{ha}{ }^{-1}+\mathrm{FYM} @ 5$ t ha ${ }^{-1} ; \mathrm{M}_{2}-\mathrm{EC}(1 / 3)+\mathrm{VC}(1 / 3)+\mathrm{GLM}(1 / 3)$ equi.to RDN; $\mathrm{M}_{3}$ - EC (1/3)+VC(1/3) + GLM (1/3) equi.to RDF; $\mathrm{L}_{1}$ - Panchagavvy @ 5\%; L $\mathrm{L}_{2}$ Bio-digester @ 20\%; $\mathrm{L}_{3}$ - Cow urine @ 10\%; $\mathrm{L}_{4}$ - Vermiwash @ 20\%; $\mathrm{L}_{5}$ - borax @ 0.2\% + $\mathrm{MgSO}_{4} @ 1 \% ; \mathrm{C}_{1}-\mathrm{RDF}-80: 40: 40 \mathrm{NPK} \mathrm{kg}+\mathrm{FYM} @ 5 \mathrm{t} \mathrm{ha}^{-1}$ 
However, at all the growth stages, enzymatic activity was found significantly higher in treatments with application of organic manures and liquid organic manures as compared to chemical fertilization. This can be attributed to cumulative effect of organic manures and liquid organic manures on proliferation of microbial population and they provide carbon and energy sources for growth and development of soil micro flora. Shwetha et al., (2009) observed that bacteria, fungi, actinomycetes and enzymes mainly dehydrogenase and phosphatase activity significantly higher in treatments supplemented with organic manures in combination of beejamruhta + jeevamrutha + panchagavya as compared to RDF + FYM. The increase in soil microbial population was due to addition of vermicompost, compost which being enriched with the beneficial organism like P-solubalizers, $\mathrm{N}_{2}$-fixers and entmophagus fungi (Indira, 1998).

Finally concluded that combined application of EC $(1 / 3)+$ VC $(1 / 3)+$ gliricidia GLM (1/3) equivalent to RDN with foliar spray of panchagavya @ 5\% improved beneficial microorganisms in soil.

\section{References}

Anonymous, 2015, Cotton Advisory Board, The cotton Corporation of India pp. 1-19.

Anonymous, 2015, Area, production and yield of cotton in India (major states). Technical Report, Directorate of Economics and Statistics, Department of Agriculture and Cooperation, New Delhi, p. 77.

Bhawalkar, V. and Bhawalkar, V., 1991, Verimiculture Biotechnology (Eds.) Bhawalkar earthworm research institute, Pune (Maharashtra), p. 41.

Bunt, J. S. and Rovira, A. D., 1955,
Microbiological studies of subantartica soils. J. Soil Sci., 6:119-122.

Indira, K., 1998, Seed technological aspects of aged seeds and production cum quantity characteristics in variety/ hybrid rice (Oryza sativa L.) Ph.D. Thesis, Tamil Nadu Agric. Uni., Coimbatore.

Kavallappa, B. N., 1989, Intensive manuring and cropping programme on soil properties, crop yield, nutrient uptake and nutritive quality of finger millet [Eluesine coracana (L.) Gaertn.] in an

Alfisol of Bangalore. Ph. D. Thesis, Univ. Agric. Sci., Bangalore, Karnataka (India).

Kuster, E. and Williams, S. T., 1964, Selection of media for isolation of Streptomyces. Nature, 202: 296-229.

Martin, J. P., 1950, Use of acid, rose-Bengal acid Streptomycin for estimating soil fungi. Soil Fungi, 69: 215-232.

Naseby, D. C. and Lynch, J. M., 1997, Rhizosphere soil enzymes as indicators of perturbations caused by enzyme substrate addition and inoculation of a genetically modified strain of Pseudomonus fluorescens on wheat seed. Soil Biol. Biochem., 29: 13531362.

Shwetha, B. N., Babalas, H. B. and Jagadesh, K. S., 2009, Effect of organics and fermented organics in biological activity of soil in soybean. J. Ecobio., 25(3): 201-207.

Singaram, P. and Kamala, K., 1995, Long-term effect of FYM and fertilizers on enzyme dynamics of soil. J. Indian Soc. Soil Sci., 43: 378-381.

Solaiappan, U., 2002, Effect of inorganic fertilizer and organic manure on cottonsorghum rotation in rainfed Vertisols. Madras Agric. J., 89 (7-9): 448-450.

\section{How to cite this article:}

Rudragouda F. Channagouda. 2019. Beneficial Microbial Load under Organic Cotton Production System. Int.J.Curr.Microbiol.App.Sci. 8(12): 1055-1062. doi: https://doi.org/10.20546/ijcmas.2019.812.134 